\title{
MÉTODO DE INVESTIGAÇÃO ESTÉTICA NO CAMPO DA ARTE E DA EDUCAÇÃO
}

AESTHETICS RESEARCH METHOD IN THE FIELD OF ART AND EDUCATION

\author{
Silvia Paulo \\ Mestranda do Programa de Pós-Graduação em Educação da Universidade Regional de Blumenau (PPGE/FURB) \\ Especialista em Tecnologia em Educação pela Pontifícia Universidade Católica do Rio de Janeiro (PUC/RJ) \\ Bolsista da CAPES na FURB. \\ E-mail: sipari_g@hotmail.com

\section{Rita Buzzi Rausch} \\ Doutora em Educação pela Universidade de Campinas (UNICAMP) \\ Docente do Programa de Pós-Graduação em Educação da Universidade Regional de Blumenau (PPGE/FURB) \\ E-mail: ritabuzzirausch@gmail.com
}

\section{RESUMO}

Nesse texto argumentamos sobre o método de investigação estética e como esse método pode tencionar as pesquisas em Arte e Educação. Objetiva caracterizar os princípios teóricos e metodológicos que fundamentam as pesquisas que se utilizam do método de investigação estética na arte e na Educação. De cunho qualitativo, realizamos uma pesquisa bibliográfica envolvendo as ideias de teóricos que tratam do assunto: Vallance (1991), Eisner (1976; 2008), Dewey $(1980 ; 2005)$ e Vygotsky (1999). Os resultados apontam que diante dos princípios teóricos as pesquisam que se utilizam do método de investigação estética são vistas como um método sensível para um trabalho sensível; conseguem suprir o pesquisador com um conjunto de princípios e experiências que forma as reações aos problemas educacionais e estimula uma discussão inteligente sobre eles; é uma crítica que faz parte de contexto e perspectiva daquilo que se sente, vê e ouve e é uma experiência estética que deve conter uma emoção. Diante dos princípios metodológicos as pesquisas são qualitativas, com uma perspectiva sensível que outros meios não dão conta; busca identificar padrões, equilíbrios e desequilíbrios, ritmos, enfim, quaisquer qualidades advindas da experiência que podem dar cor a cada julgamento da situação; pode ter todas as tipicidades que encontramos em qualquer outra pesquisa educacional. Outro fator relevante a destacar sobre os resultados são que as técnicas de observação e descrição derivam dos seguintes tópicos: ênfase seletiva, símile e metáfora, comparação incidental, técnica implícita e adjetivos redundantes. Tópicos esses que podem ser utilizados em uma pesquisa educacional como categorias de análise.

Palavras-chave: Método de investigação estética. Arte. Educação. Estética. 


\section{ABSTRACT}

This text arguments about aesthetics research method and how this method may intend to research in Art and Education. Objectively characterize the theoretical and methodological principles that underlie the research that use the aesthetics research method in art and education. A qualitative approach, we conducted a literature search involving theoretical ideas dealing with the subject: Vallance (1991), Eisner (1976; 2008), Dewey $(1980 ; 2005)$ and Vygotsky (1999). The results show that on the theoretical principles of research that use the aesthetics research method are seen as a sensitive method for sensitive work; can supply the researcher with a set of principles and experiences that shape reactions to educational problems and stimulates an intelligent discussion about them; It is a critical part of the context and perspective of what feels, sees and hears and is an aesthetic experience which should contain an emotion. Given the methodological principles are qualitative research, with a sensitive perspective that other mediums do not realize; seeks to identify patterns, balances and imbalances, rhythms, in short, any qualities arising from the experience that can give color to each judgment of the situation; You can have all the typicalities we find in any other educational research. Another important factor to highlight the results are the techniques of observation and description are derived from the following topics: selective focus, simile and metaphor, compared incidental, implicit technique and redundant adjectives. Those topics that can be used in an educational research as analytical categories.

Keywords: Art. Education. Aesthetics.

\section{INTRODUÇÃO}

Método novo ou apenas adormecido por um tempo pelas incongruências que os profissionais em educação achavam que ele possuía? Como podemos ajudar os acadêmicos a reconhecer os modos sobre os quais nós exprimimos e recuperamos o significado, não só nas artes, mas também na educação? Como podemos iniciá-los na arte de fazer educação? É oportuno ressaltar que os estudos referentes à investigação estética são recentes na literatura educacional, e compreendem, em sua maioria, pesquisas elaboradas em língua inglesa, ainda sem tradução para o português.

Nessa perspectiva trazemos nossa pergunta de partida para a abordagem desse trabalho: Quais os princípios teóricos e metodológicos que fundamentam as pesquisas que se 
utilizam do método de investigação estética no campo da arte e da Educação? Objetiva caracterizar os princípios teóricos e metodológicos que fundamentam as pesquisas que se utilizam do método de investigação estética na arte e na Educação.

Esse trabalho surgiu do interesse de aprofundar nossas leituras no sentido de desenvolver aprendizagem quanto ao método de investigação estética percebido em leituras prévias sobre o tema estética. Com isso observamos a recorrência de citações de autores como Vallance (1991) e sua abordagem de um método de investigação estética em relação ao procedimento da pesquisa.

Outro intento se caracterizou por ser um método emergente desenvolvido a partir dos princípios da crítica à pintura e outras artes plásticas. Esse método obedece a vários princípios norteadores, ele é regido com certa flexibilidade, podendo ser estruturado de diversas maneiras. Conforme Vallance (1991, p. 162), diz que tais princípios norteadores são baseados em determinados tipos de Crítica de Arte e adaptados para a investigação em Educação.

Os principais teóricos utilizados nesse trabalho que tratam do método de investigação estética são: Elisabeth J. Vallance (1991; 1975), Elliot Eisner (1976; 2008), Dewey (1980; 2005) e Vygotsky (1999). Porém, utilizamos mais alguns teóricos para que pudéssemos explicar o método de investigação estética no campo da arte e da educação.

Vale salientar que não é nossa intenção apresentar as diversas acepções que o termo estético assumiu desde o início de suas discussões, mas sim caracterizar os princípios teóricos e metodológicos que fundamentam as pesquisas que se utilizam do método de investigação estética na arte e na Educação.

Para isso organizamos a estrutura deste texto em seis partes: introdução que traz a pergunta de partida, os objetivos, a justificativa, a metodologia e os principais teóricos utilizados no trabalho; o item seguinte traz como título: primeiras palavras para contextualizar; esse item é utilizado para situar o leitor quando a conceituação de estética e de arte; o item experiência estética traz conceituações de alguns autores sobre qualidades, experiência e reação estética e ainda sobre o termo experiência utilizada em Dewey; o próximo item é intitulado falando sobre crítica em arte que menciona o crítico de arte e o crítico educacional; a seguir o título investigação estética e crítica à arte segundo Vallance (1991) coaduna os principais princípios teóricos e metodológicos do método de investigação estética e no item considerações finais expomos mais algumas ideias da autora Vallance, (1991) e fizemos um apanhado geral dos princípios teóricos e metodológicos. 


\section{PRIMEIRAS PALAVRAS PARA CONTEXTUALIZAR}

Por não contribuir diretamente para a produção de bens de consumo industriais, a arte continua sendo relegada a segundo plano nos currículos escolares. Todavia, ela pode conduzir à formação de pessoas mais sensíveis à sua condição humana e à sua realidade levando-as a pensar de maneira crítica o contexto em que são inseridas. Ou seja, a educação dos sentimentos proporcionada pelos símbolos estéticos não se esgota em si mesma, uma vez que favorece o desenvolvimento da capacidade intelectual e racional do ser humano.

Como nos explica Duarte Jr. (2001, p. 13) a palavra estética deriva da palavra grega aisthesis ${ }^{1}$, "indicativa da primordial capacidade do ser humano de sentir a si próprio e ao mundo num contexto integrado." O mesmo autor acrescenta, em outra obra sua, que a experiência estética pode ser entendida como "uma suspensão provisória da causalidade do mundo, das relações conceituais que nossa linguagem forja. Ela se dá com a percepção global de um universo do qual fazemos parte e com o qual estamos em relação “، (1988, p. 91).

Cogitamos fazer-se necessário trazer algumas conceituações de arte. Segundo, Hard, arte é a

experiência em seu fluxo normal, dia após dia, é provável que não seja tão dramático para a maioria de nós. Muitas vezes ela não tem enredo: ela consegue não ter emoção não há anti-clímax deprimente. Ser experiência de certeza, primitivo e pioneiro no âmbito das condições geralmente precárias da fronteira oferecidos e oferece muito que é estimulante e excitante (HARD, 1972, p. 233, tradução nossa).

Frayze-Pereira prossegue citando Dufrenne ${ }^{3}$, quando este último defende que "não são apenas as teorias da arte que hesitam em atribuir uma essência ao objeto estético, mas a própria prática dos artistas é que desmente a todo o momento de qualquer definição." Não é raro que a tentativa de definição da arte acabe gerando erros e más-interpretações da atividade artística. Deixemos que novamente Frayze-Pereira nos explique ser

um erro muito frequente [...] considerar a Arte ou admitir como conceito geral e definidor da Arte um programa particular de arte, uma poética. Segundo o grande esteta italiano Luigi Pareyson, esse engano é frequente e consiste em tomar a parte pelo todo, por exemplo, quando se diz que a Arte é expressão do eu profundo do artista, sem se dar conta que essa é uma ideia que surge com o Romantismo no começo do século XIX, e não antes (FRAYZE-PEREIRA, 2004, p. 85).

Sendo assim, a natureza do objeto estético dificilmente pode ser compreendida a partir do que é costumeiramente entendido como sendo uma obra de arte. Ainda conforme Dufrenne (2005, p. 87), “a obra só se constitui inteiramente no que tange ao seu sentido, através do 
espectador". Daí concluir-se que a qualidade do sentimento que um espectador experimenta frente a uma obra de arte é pessoal e única. Outra conceituação de arte é a partir da ideia de símbolo e quem nos dá é Langer (1980, p. 88): a "arte é a criação de formas simbólicas do sentimento humano." Indo ao encontro da pensadora americana, apresentamos a ideia de Duarte Jr. (1988, p. 89), para quem “a obra de arte constitui uma objetivação dos sentimentos, isto é, a sua concretização em um símbolo.” Ainda segundo Duarte Jr. (2001, p. 33), a arte atua "levando-nos não apenas a descobrir formas até então inusitadas de sentir e perceber o mundo, como também desenvolver e acurar os nossos sentimentos e percepções acerca da realidade vivida".

A arte para a concepção materialista evidencia e traduz o mundo enquanto cria. Ao mesmo tempo em que a obra de arte é uma expressão da realidade ela cria a realidade, uma realidade que existe apenas na obra, não antes dela ou depois dela. Logo, para Vygotsky (1999, p. 307), “[...] a natureza da arte sempre implica algo que transforma que supera o sentido comum, e aquele mesmo medo, aquela mesma dor, aquela mesma inquietação, quando suscitadas pela arte, implicam a algo a mais acima daquilo que nela está contido." Para conseguir articular o material e o simbólico, a natureza e a cultura somente um modo dialético de pensar pode dar conta, pois o significado atribuído a estética é ao mesmo tempo contraditório e paradoxal.

Por fim, compreendemos que arte é algo amplo porque é tudo o que o ser humano pode sentir e consegue explicar. É aquilo que pode passar pela mente humana de forma que ninguém pode entender, mas consegue expressar pela arte, porque arte é sentimento daquilo que se pensa ter pensado, são símbolos demostrados por meio de um desenho com uma composição bem elaborada ou ainda apenas demonstrada por meio do abstrato. Arte é pensar em sua intimidade várias palavras e transformá-la em poesia. É conseguir escrever o texto que se tem em mente com os mesmos sentimentos que sentiu quando apenas estava no pensamento.

\section{EXPERIÊNCIA ESTÉTICA}

Sem a função de culto voltada para a finalidade que ascende à arte que não seja por meio da formação, da interioridade e da sensibilidade do indivíduo, mais de um sujeito coletivo organizado mediante experiências estéticas faz-se pensar em novas linguagens quando se trata de estética. Portanto, a necessidade do texto corrobora para uma explanação possível, porém breve sobre a experiência estética. 
A compreensão de que episódios em nossas vidas podem ser carregados de qualidades estéticas, só é possível devido aos avanços das discussões sobre estética ao longo do tempo. Segundo Townsend (1997, p. 10), "a estética nasce da tentativa de explicar o papel que as sensações e as emoções desempenham no pensamento humano" assim, a estética é o estudo destas sensações e emoções perante objetos, podendo ou não ser objetos de arte. Ao deparar-se com um objeto estético, existe a possibilidade de instaurar-se uma condição específica de forma a proporcionar a experiência estética.

Segundo Dewey (1980), uma experiência possui qualidades únicas que lhe conferem uma unidade distinta, como falar daquela comida, aquele desentendimento com o melhor amigo ou aquela falta coletiva dos alunos. Estas qualidades únicas são qualidades estéticas.

A discussão de Vygotsky em torno do que é estética fica mais para o campo dos sentimentos. Para ele, "a percepção estética supõe um movimento que envolve contradição, transformação e que se assemelha ao movimento de catarse, no qual acontece uma espécie de conversão de sentimentos". A "[...] reação estética supõe uma complexa transformação dos sentimentos" (VYGOTSKY, 1999, p. 270). Vygotsky (1999) menciona também que a educação voltada à estética torna-se um aprendizado criador por se fundamentar no entendimento e percepção, possibilitando ao indivíduo percebê-la como componente cultural humano, ampliando sua experiência pessoal.

A experiência estética acontece no momento de apreensão do objeto estético. Duarte Junior (1988, p. 90-94) apresenta uma diferença entre a experiência prática e a experiência estética. $\mathrm{Na}$ experiência prática estão presentes as preocupações objetivas, funcionais e práticas de nosso cotidiano e na experiência estética essas preocupações são suspensas e privilegiam outros valores, outros sentidos que nos fazem ver em um fato comum um potencial sensível. A experiência estética não está condicionada à funcionalidade de um objeto, mas a observações desautomatizadas, podendo ser agradáveis ou não, porém, possuem a capacidade de propor um novo olhar a algo que nos é comum. Assim, Dewey (1980, p. 93), afirma que o elemento de padecimento da experiência estética "implica uma reconstrução que pode ser penosa. Que a fase de padecimento necessário seja em si própria prazerosa ou dolorosa é algo que dependerá de condições particulares”.

Durante a experiência estética, deixamos de nos preocupar com questões práticas como: a cama serve para dormir, o sofá para sentar, entre outras, e nos dedicamos ao deleite do prazer estético ou a angústia do desprazer estético. No prazer estético, podemos observar atentamente a beleza das curvas entalhadas no entorno da cama ou o desenho e as cores do sofá. 
Durante a experiência estética as questões práticas não deixam de existir; entretanto, o sujeito consegue presenciar qualidades que se destacam. Para Vallance (1991), uma destas qualidades seria a possibilidade de gerar um insight, que pode ficar armazenado na memória, aguardando um momento em que possa influenciar as decisões, mesmo que em situações diferentes das experienciadas. Esta reação estética permanece em repouso, criando intervalos no jeito prático de ver as coisas.

Cogitamos que a experiência estética pode ser dolorosa ou não dependendo da particularidade da situação ocorrida. Um exemplo se faz necessário para que o leitor entenda a nossa ideia de experiência estética. Imagine um professor na sala de aula com 20 alunos. Certo dia, após o término da aula um grupo de 9 alunos abordam o professor para discutir os procedimentos e conteúdos ensinados pela professora nas aulas. O professor se defende mostrando aos alunos a ementa da disciplina e seu planejamento diário. A conversa termina e nenhuma das partes fica satisfeita. Nas próximas aulas o clima fica tenso durante as explicações, trabalhos e avaliações a serem feitos. O professor envolvido com a situação, atento para os detalhes, reflete sobre o ocorrido. Após um tempo o professor muda seu planejamento e a maneira como desenvolve as aulas. Uma crítica negativa acarreta em uma atitude positiva. $\mathrm{O}$ professor se sensibilizou para que a mudança ocorresse, ou seja, o professor passou por uma experiência estética.

\section{FALANDO SOBRE CRÍTICA EM ARTE}

Não existe crítica pela crítica. Uma crítica eficaz requer a utilização de conhecimento especializado. Igualmente quando se pensa na crítica logo se imagina que a educação como um campo de estudo não tem; como faz a literatura, a música, as artes visuais; um ramo específico chamado crítica educacional. Não temos nas universidades programas que demandam preparação aos críticos educacionais. Urge um trabalho efetivo que crie uma nova forma de olhar para os fenômenos que constituem a vida educacional dentro das salas de aula.

Segundo Eisner (1976), existem três aspectos principais de crítica educacional, quais sejam:

aspecto descritivo: é um esforço para caracterizar os aspectos puramente descritivos dos fenômenos; o aspecto interpretativo representa um esforço para compreender o significado e a importância que as várias formas de ação têm para os indivíduos em um ambiente social e o terceiro aspecto da crítica é avaliativa (EISNER, 1976, p. 143, tradução nossa) 
Esses aspectos diferenciam fortemente o trabalho do educador crítico no sentido de avaliar criteriosamente os valores educacionais exigindo não somente a capacidade de ver como funciona o trabalho planejado para a sala de aula, mas também como se interpretam as variáveis significações aparentes no todo constituinte a uma atividade em curso. Sendo assim, a tarefa do crítico, conforme Eisner (1976), não é simplesmente de um observador neutro e desinteressado. O crítico vai observar e tirar conclusões sobre o caráter da prática educativa.

Nisso, o sentido da crítica é; como nos conta Eisner (1976), empírica. Mais empírica do que se pode imaginar porque quando um crítico educacional assiste a um educador em sala de aula necessita descrever, interpretar e avaliar os fenômenos da qual assistiu. Será que o entusiasmo do professor contagia? Será que os alunos apoiam uns aos outros? A sala de aula é uma significante de sentidos para todos? Esse emaranhado de discussões e atenções se torna uma política educacional desejável a todos os grupos educacionais desde que seja tratado de forma fidedigna. Isto significa reconhecer que as formas que os indivíduos criam, as formas de arte, bem como as formas de ciência, oferecem oportunidades únicas para concepção e expressão, e, portanto, para a comunicação (EISNER, 1976).

Encerramos o parágrafo com Duarte Jr. que afirma

se à arte cabe o papel de instrumento para a educação da sensibilidade e para a descoberta de outra forma de significação que não a conceitual, parece necessário que sua inserção em processos educacionais se faça em estreita comunhão com o desenvolvimento de valores éticos e de um raciocínio lógico (DUARTE JR., 2001, p. 213).

Portanto, a arte não é uma linguagem que comunique conceitos, antes, é expressão de sentimentos. É a tentativa de concretizar, numa forma, o mundo dinâmico e inefável dos sentimentos humanos (DUARTE JR., 1988, p. 88). Em uma obra de arte os sentimentos são apresentados para que possamos senti-los, revivê-los e memora-los. Esses fatos são expressos de maneira íntegra pela poetiza Silvia Paulo, em seu "Meu coração; teu coração, minha razão; tua razão ${ }^{4}$.

\section{[...] encoberto por ternura apaixonei-me...}

No colorido das manhãs vistas por lentes coradas, tudo era festa, um rebuliço! No coração a calma de amar, no olhar a inconstância da dúvida.

De repente; de sobre salto um tombo desenha obscura imagem,

Ascendendo a tristeza no peito; fotografias existentes, pra mim ambivalentes, cristais no tempo a revelar...

Mentiras, angústias e sofreguidão; tela antiga demonstrando o que ainda não terminou... Desolações, previsões e espera, olhos destinados a ver

Com olhos livres [...] (PAULO, 2013, p. 18-19) 


\section{INVESTIGAÇÃO ESTÉTICA E CRÍTICA À ARTE SEGUNDO VALLANCE}

Pessoas como Galton na Inglaterra e Helmholtz e Fechner na Alemanha estavam entre os seus cabecilhas, e mesmo William James, Charles Spearman e G. Stanley Hall fizeram uma passagem pela Europa, para aprender os segredos e os métodos daqueles que procuravam criar uma ciência da mente (EISNER, 2008).

Acrescentamos a essa lista Vallance (1991) e sua abordagem de investigação estética que pretende explicar um método com o mesmo intuito: "criar uma ciência da mente" (EISNER, 2008, p. 6), isto é, uma ciência por onde atravessam não somente a razão do ser humano, mas o sentir, o ouvir, o ver de forma crítica.

Assim, a investigação estética é um modo de investigação qualitativa que arrisca apresentar uma carga suave, ou seja, apresenta problemas especiais para se tornar um manual de normas sobre investigação em literatura, por exemplo, entre outras áreas (VALLANCE, 1991). Ainda para Vallance (1991), a investigação estética é vista como um meio para o entendimento do fenômeno educacional, que trabalha em paralelo e contra a tradição que busca princípios científicos para guiar as políticas e práticas que afetam a educação escolar.

A investigação estética para Vallance (1991) baseia-se em tipos de sensibilidades e questões que os educadores e outros tacitamente usam em muitas considerações, ou seja, o modo útil de adotar a investigação estética depende de experiências passadas e das experiências sobre um dado assunto (por exemplo: desenvolvimento estético, literatura, etc.) que cada indivíduo quer estudar.

Desmistificar o conceito de investigação estética é torná-la possível ao trabalho dos pesquisadores que sentem a necessidade cada vez mais urgente de um método sensível para um trabalho sensível. O trabalho com o método de investigação estética pode ser de grande valia como uma abordagem metodológica que guia um estudo com uma perspectiva sensível que outros meios podem não dar conta.

Esse método pode dar sentido a interpretações educacionais reunidas por outros meios. Dado que muitas ações educacionais são tomadas espontaneamente e refletem as sensibilidades e predisposições dos professores, como determina Vallance (1991), quaisquer esforços por sistematizar as variáveis na educação serão limitados por esses fatores incontroláveis. Considerando isso, tentativas de pesquisa em educação (incluindo a literatura, atuação e formação de professores, etc.) devem refletir uma perspectiva que admita esta condição e se propõe a trabalhar com ela (VALLANCE, 1991). 
Vallance se dedica a traçar paralelos diretos entre técnicas de critica da arte e outro dado assunto; afirma examinar um evento educacional - a disposição da sala de aula, um momento de ensino, um evento literário - como um único evento, análogo a uma obra de arte não replicável, nesse sentido, explicitamente é uma resposta estética do investigador ao evento (VALLANCE, 1991). Sobre a natureza da resposta estética ao evento existem muitas gerações de estetas ${ }^{5}$ que se referem ao assunto ${ }^{6}$. A resposta estética segundo Vallance (1991) representa uma pausa em nosso modo prático de avaliar o ambiente em nossa volta e ser impressionado ao ter a chance de ver as coisas de outro modo. Sempre haverá uma surpresa na resposta estética, que é como diz Vallance um insight inesperado e prazeroso sendo isso uma recompensa.

Conforme Vallance (1991), a investigação estética tem relevância em pesquisas sobre estética. Podemos querer pesquisar sobre, por exemplo, o desenvolvimento estético por meio da literatura e com isso discorrer sobre qualidades estéticas (positivas ou negativas) de uma série de fatores revelados pelo estudo, para cada caso, a investigação estética se concentrará em certas qualidades e princípios que moldam nossa reação à situação; buscarão identificar padrões, equilíbrios e desequilíbrios, ritmos, enfim, quaisquer qualidades advindas da experiência que podem dar cor a cada julgamento da situação. O que importa é que a investigação estética nos deixará livre para responder às qualidades que poderão nos surpreender dependendo da nossa experiência formada no passado e no momento do acontecimento da qualidade.

Assim, continua nos contando Vallance (1991), que críticos de arte passam longos anos apreendendo a ver obras de arte, e sua resposta à pintura é formada pela experiência. $\mathrm{O}$ crítico que demonstra mais experiência não necessariamente verá a obra de arte de "maneira correta" (grifo nosso), mas esta será mais defensiva porque esse crítico construiu um repertório de outras referências e linguagens, pelas quais nos explica sua reação. A tarefa de treinar uma investigação estética é suprir o pesquisador com um conjunto de princípios e experiências que formará as reações aos problemas educacionais e estimulará uma discussão inteligente sobre eles (VALLANCE, 1991).

Alguns pesquisadores podem ter uma má interpretação quanto ao método de investigação estética por causa da sua construção semântica, por implicar com sua forma de interpretar o estudado ou ainda por implicar que o processo de investigação em si tenha qualidades estéticas. Na verdade, Vallance (1991) alerta o leitor, que a investigação estética pode mesmo ter todas as tipicidades que encontramos em qualquer outra pesquisa educacional: técnicas corroborativas, leva muito tempo, trabalho duro e não necessariamente a experiência estética agradável que poderíamos esperar que fosse. 
Perseguindo a fala de Vallance (1991), precisamos ter em mente que a informação disponibilizada por meio da investigação estética, ainda que imensamente valiosa e contribuinte na tomada das decisões já mencionadas, não é o suficiente; outras informações mais mecânicas e logísticas devem ser consideradas também. Os pesquisadores que possivelmente adotem a investigação estética devem ser sensíveis a esta qualidade intrínseca da abordagem; pois ela trabalha melhor quando complementa resultados de investigação tradicional com recortes de outras qualidades que também nos ajudam a entender a situação.

Façamos uma analogia para ajudar a esclarecer o exposto no parágrafo precedente: o pesquisador que usa métodos de investigação estética trabalha de modo parecido com o crítico de arte. $\mathrm{O}$ crítico baseado nas tradições artísticas de um período ou estilo particular, fala como um expert naquele dado corpus do trabalho, e age como uma espécie de tradutor ou ponte para o público que é menos bem-informado (VALLANCE, 1991). O crítico precisa conhecer o assunto para que possa emprestar seu entendimento a alguém bem como o professor diante do contexto escolar ao qual trabalha.

Vallance (1991, p. 21) menciona Também sobre os princípios gerais da investigação estética e diz: "muitos desses princípios é o modo mais fácil de pensar a este respeito imaginando as analogias entre o mundo de arte e o mundo escolar". Os princípios que Vallance descreve para essa analogia são:

\footnotetext{
ambos são, produtos da construção humana; ambos são meios de comunicação entre seus criadores e um grupo; ambos são produtos resultantes de um processo de resolução de problemas; ambos dependem, por seu significado, de um encontro com um grupo porque ambos promovem situações nas quais a resposta do grupo é solicitada; ambos dão à experiência do grupo conjuntos de informações; ambos podem provocar reações fortes, quando são bem sucedidos em atrair a atenção de um grupo; ambos podem ser posicionados dentro da tradição da história e suas mudanças de estilo - inovar e ambos solicitam crítica (VALLANCE, 1991, p. 100)
}

Vallance (1991) nos surpreende falando que tanto o mundo da arte quanto o mundo escolar podem trabalhar com técnicas de observação e descrição solicitando a crítica, se utilizarem-se dos seguintes tópicos:

Ênfase seletiva: referir-se a cada aspecto de uma pintura; símile e metáfora: a descrição vivida e crítica baseiam-se constantemente em comparações com outras características de nossa experiência ou de imagens evocadas pelo trabalho; comparação incidental: uma breve referência (nos poupando de uma exaustiva comparação) a trabalhos similares dentro da mesma tradição pode esclarecer o impacto da obra para o crítico; técnica implícita: poderá tacitamente sugerir como um dado trabalho teria sido criado - mais para comunicar sua aparição do que como uma declaração precisa da técnica realmente usada; movimento implícito: críticos de arte são notórios pelos verbos "coloridos" que usam, e por verem ação que, obviamente não podem ser apresentada em uma peça estática: "cores chocando-se para então 
fundir-se", sombras "crescendo" e outras frases como estas comunicam o dinamismo visual de uma peça estática. Críticos educacionais podem fazer o mesmo; adjetivos redundantes: críticos de arte são notórios também por sua linguagem cheia de floreios que se concentra no particular. Do mesmo modo, críticos educacionais podem suscitar comentários sobre sua fala/escrita redundante (VALLANCE, 1991, p. 100, grifo nosso).

Quando um pesquisador se atém a detalhes qualitativos a qualidade da investigação estética os encoraja a criticar o evento educacional em questão, do contrário, a pesquisa educacional tradicional leva o pesquisador para longe desses detalhes. Um pesquisador pode demorar o mesmo espaço de tempo para criticar uma obra literária e uma obra de arte e ainda ser esteticamente morto, do contrário também é válido.

Nesse sentido, nada melhor para demonstrar a diferença entre pesquisas quantitativas e pesquisas qualitativas do que as diferentes lógicas que sustentam as abordagens de amostragem, como afirma Patton (1990). O autor sustenta que a lógica e o poder de amostragem proposital reside na seleção e em casos ricos em formação para um estudo em profundidade. Casos ricos em informação são aqueles a partir do qual se pode aprender muito sobre questões relevantes para a investigação, assim, vale a amostragem propositada para categorizar as análises de uma pesquisa (PATTON, 1990). Um exemplo que Patton descreve

\footnotetext{
se o objetivo de uma avaliação é aumentar a eficiência de um programa em alcançar os grupos menos favorecidos, podem-se aprender muito mais, concentrando-se em profundidade na compreensão das necessidades, interesses e incentivos de um pequeno número de selecionados; como: famílias pobres. Do que através da recolha de informações padronizadas de uma grande amostragem estatisticamente representativa de todo o programa (PATTON, 1990, tradução nossa).
}

O propósito de amostragem proposital é selecionar casos ricos em informação cujo estudo vai iluminar as questões pesquisadas. Existem várias estratégias diferentes para selecionar propositadamente casos ricos em informação, portanto, a lógica de cada estratégia serve a uma determinada finalidade de avaliação.

\section{CONSIDERAÇÕES FINAIS}

Considerando os diálogos precedentes desse texto, Vallance (1991) ainda nos traz uma pergunta: Como sabemos se um trabalho em pesquisa educacional tradicional é "exemplista" ou é fraco? Para responder a essa pergunta Vallance empresta o que é estabelecido na terminologia que usamos em pesquisa educacional tradicional: a pesquisa educacional experimental tradicional busca alguns padrões de confiabilidade, verificabilidade, validade, 
replicabilidade, generalidade e assim por diante - todos esses pontos se referindo a testes de controle variável e consciência metodológica. Esses mesmos padrões não podem ser aplicados, como nos mostra os estudos de Vallance (1991), à investigação estética porque não esperamos que dois críticos de arte vejam as mesmas coisas em uma exposição de arte e realmente nos sentiríamos enganados se estes o fizessem - esperamos que os críticos produzam insights diferentes e nos ajudam a ver o evento de tantas formas informativas quanto possível.

Do mesmo modo um trabalho de pesquisa deve ser validado estruturalmente para ser efetivo; a escolha do foco pelo crítico e o uso de metáforas e outras técnicas devem vir juntos em um argumento coerente contra o qual o leitor possa testar suas percepções. Um pesquisador precisa estar envolvido com a situação de estudo, atento aos detalhes, refletindo sobre o ocorrido e sobre o que continua a acontecer em sua volta quando está a pesquisar, algo próximo do que Dewey (1980, p. 92) colocou como “o interesse pelas coisas que acontecem pelo caminho, condições que aceleram e retardam seu movimento em relação a seu término".

Diante do que nos conta Vallance sobre o método de investigação estética percebe-se o "se dar conta" anunciado por Dewey (2005); que para o pesquisador, importa conhecer os princípios descritos nesse texto e mais alguns critérios que Vallance (1991) diz ser de grande importância para que um trabalho que envolve estética e que seja realmente eficiente ao comunicar as qualidades mais importantes de uma dada pesquisa. São três critérios: apresentar a pesquisa em linguagem moderna e livre de jargão; boa escrita e perspectiva generalista e a sensibilidade de ater para detalhes.

Um pesquisador que utiliza o método de investigação estética é responsável por contextualizar, porque a crítica é em parte, uma questão de contexto e perspectiva daquilo que se sente, vê e ouve. Se o pesquisador se sensibiliza pelas qualidades estéticas da experiência pela qual atravessa consegue refletir suas ações futuras necessárias com mais determinação e confiança. Assim, Dewey (2005) nos conta que a experiência estética deve conter uma emoção, que se faça presente em toda ela.

O método de investigação estética oferece uma perspectiva da pesquisa que outros métodos frequentemente evitam. Esse método pode ajudar os pesquisadores e educadores a ver mais claramente com o que eles estão lidando; como estão reagindo diante dessa ou aquela situação e por que e, ainda dar conta de suprir os obstáculos comparando alternativas. Poucas instituições de ensino e poucos pesquisadores se utilizam da abordagem metodológica investigação estética - mas aqueles dentre nos envolvidos com essa abordagem procuram compreende-la e usa-la em pesquisas. 
Por fim, elucidamos os principais princípios teóricos do método de investigação estética: é uma ciência por onde atravessam não somente a razão do ser humano, mas o sentir, o ouvir, o ver de forma crítica; é um método sensível para um trabalho sensível; são o ver as coisas de outro modo; é conseguir suprir o pesquisador com um conjunto de princípios e experiências que formará as reações aos problemas educacionais e estimulará uma discussão inteligente sobre eles; é uma crítica que faz parte de contexto e perspectiva daquilo que se sente, vê e ouve e é uma experiência estética que deve conter uma emoção.

Em contraponto trazemos os principais princípios metodológicos: investigação qualitativa que pode ser usada em uma abordagem metodológica que guia uma pesquisa com uma perspectiva sensível que outros meios não dão conta; investigação estética que se concentra em certas qualidades e princípios que moldam a reação à situação; buscando identificar padrões, equilíbrios e desequilíbrios, ritmos, enfim, quaisquer qualidades advindas da experiência que podem dar cor a cada julgamento da situação, que pode ter todas as tipicidades que encontramos em qualquer outra pesquisa educacional: técnicas corroborativas, leva muito tempo, trabalho duro; é um método que trabalha de modo parecido com o crítico de arte.

Porém, não podemos esperar que dois críticos de arte vissem as mesmas coisas em uma exposição de arte e realmente nos sentiríamos enganados se estes o fizessem - esperamos que os críticos produzam insights diferentes e nos ajudam a ver o evento de tantas formas informativas quanto possível. Reflete-se sobre o ocorrido, sobre o que continua a acontecer em nossa volta e apresenta alguns critérios como: apresentar a pesquisa em linguagem moderna e livre de jargão; boa escrita e perspectiva generalista e a sensibilidade de ater para detalhes.

Para encontrar qualidades estéticas em uma pesquisa, é necessário utilizar um método apropriado, optando-se pela investigação estética e para isso a melhor maneira é optar pela amostragem proposital de intensidade. Segundo Patton (1990), essa amostragem consiste em obter casos específicos que manifestam o fenômeno de interesse intensamente. Com base em Vallance $(1975 ; 1991)$, as técnicas de observação e descrição derivam dos seguintes tópicos: ênfase seletiva, símile e metáfora, comparação incidental, técnica implícita e adjetivos redundantes. Tópicos esses que podem ser utilizados em uma pesquisa educacional como categorias de análise.

\section{NOTAS}

1 O sentido dos sentidos, p.13. 
2 Fundamentos estéticos da educação, p. 91.

3 Dufrenne apud Frayze-Pereira, 2005.

4 Nas entrelinhas de meus pensamentos, p. 18-19 (Blumenau, 3 de maio, 2013).

5 Pessoa versada em estética ou que tem sensibilidade artística.

6 Recomenda-se ao leitor os trabalhos de Beardsley (1966, 1970), Bullough (1957), Dewey (1959), Eisner (1972), Langer (1951, 1957), Meager (1963), Osborne (1955), Pepper (1945), Rader (1060), Rosenberg (1966), Smith (1966), Sparshott (1966), Stolnitz (1970), dentre outros (VALLANCE, 1991).

\section{REFERÊNCIAS}

DEWEY, John. Experiência e Educação. Trad. de Anísio Teixeira. 3 ed. Nacional: São Paulo, 1980. (atualidades pedagógicas; v. 131). 97p.

. Art as experience. New York: Perigee, 2005.

DUARTE JR., João Francisco. Fundamentos estéticos da educação. 2 ed. Campinas, São Paulo: Papirus, 1988, 150p.

. O sentido dos sentidos: a educação (do) sensível. Curitiba: Criar, 2001.

DUFRENNE, Mikel. Estética e filosofia. São Paulo: Perspectiva, 2004.

EISNER, E. W. Educational Connoisseurship and Criticism: Their Form and Functions in Educational Evalucition. Journal of Aesthetic Education, v. 10, n. 3/4, jul/oct., 1976, p. 135-150.

EISNER, E. W. O que pode a educação aprender das artes sobre a prática da educação? Currículo sem Fronteiras, v.8, n.2, jul/dez., 2008, p. 5-17.

ESTETA. Definições encontradas. Disponível em: <http://www.dicionarioinformal.com.br/ esteta>. Acesso em: 02 nov. 2015.

FRAYZE-PEREIRA, João A. Arte, Dor: Inquietudes entre Estética e Psicanálise. São Paulo: Ateliê Editorial, 2005.

HART, Joseph K. Inside experience: A Naturalistic Philosophy of Life and the Modern World NY Longmans, Green 1927, 294p.

LANGER, Susanne K. Sentimento e forma. São Paulo: Perspectiva, 1980.

PATTON, M. Qualitative evaluation and research methods. 2. Ed. Newbury Park: Sage, 1990.

PAULO, Silvia. Nas entrelinhas de meus pensamentos. Blumenau, 3 de maio, 2013.

TOWNSEND, D. Introdução à Estética: histórias, correntes e teorias. Lisboa: Edições 70, 1997. 
VYGOTSKY. L.S. Psicologia da Arte. São Paulo: Martins Fontes, 1999.

VALLANCE, E. J. Aesthetic criticism and curriculum description. 1975, 259 f. Tese. (Doutorado em Filosofia). Stanford University, Stanford, 1975.

VALLANCE, E. J. Aesthetic inquiry: art criticism. In: SHORT, E. C. (Ed.). Forms of curriculum inquiry. New York: State University of New York, 1991. p. 153 - 172. 